\title{
Tradición clásica en el Mercurio Peruano (1791- 1795): lecturas de una sociedad ilustrada colonial sobre los clásicos de Grecia y Roma
}

\section{Classical Tradilion in Mercurio Peruano (1791-1795): Readings of an Enlightened Colonial Society on the Classics of Greece and Rome}

\author{
María Gabriela Huidobro Salazar \\ Universidad Andrés Bello, Santiago, Chile \\ Contacto: mhuidobro@unab.cl \\ http://orcid.org/0000-0001-9980-6175
}

\section{RESUMEN}

A través de la identificación y revisión de citas y alusiones a obras y autores de la Antigüedad Clásica grecorromana en el periódico Mercurio Peruano (1791-1795), el artículo parte desde una aproximación dada por la historia de la lectura y los estudios de Recepción Clásica, para analizar los modos de aproximación y niveles de lectura que la sociedad letrada de Perú, a fines del siglo XVIII, pudo haber desarrollado para entrar en contacto y diálogo con la cultura clásica. El estudio se contextualiza mediante un análisis de los títulos de obras clásicas y sobre el mundo antiguo que pudieron circular en los ámbitos letrados y por el sistema educacional del mundo colonial. Con ello, demuestra que los autores y lectores del Mercurio Peruano tuvieron un conocimiento múltiple, dinámico y complejo de los autores clásicos y de sus obras, a los que se acercaron a través de lecturas directas, indirectas y medidas. De este modo, se apropiaron de ellos como voces de autoridad y como principios productores de sentido e identidad para la formulación y legitimación de sus propios discursos locales e ilustrados, dando cuenta de la vigencia de la cultura clásica antigua, para entonces, en el circuito letrado de la sociedad colonial.

Palabras clave: Recepción clásica; Mercurio Peruano; Prácticas de lectura

\section{Daniel Ignacio Nieto Orriols}

Universidad Andrés Bello, Santiago, Chile

Contacto: daniel.nieto@unab.cl

https://orcid.org/0000-0003-4403-5849

\section{ABSTRACT}

Through the identification and review of citations and allusions to works and authors of the Greco-Roman Classical Antiquity in the newspaper Mercurio Peruano (1791-1795), the article starts from an approach given by the history of reading and by Classical Reception Studies, to analyze the ways of approaching and levels of reading that the literate society of Peru, at the end of the 18th century, could have developed to enter into contact and dialogue with classical culture. The study is contextualized through an analysis of the titles of classical works and about the ancient world that could circulate in the literate fields and through the educational system of the colonial world. With this, it shows that the authors and readers of the Mercurio Peruano had a multiple, dynamic and complex knowledge of the classical authors and their works, which they approached through direct, indirect and measured readings. In this way, they appropriated them as voices of authority and as principles that produce meaning and identity for the formulation and legitimation of their own local and enlightened discourses, accounting for the validity of ancient classical culture, by then, in the enlightened circuit of the colonial society.

Keywords: Classical Reception; Mercurio Peruano; Reading practices 


\section{Introducción}

En enero de 1791, la sociedad colonial peruana, especialmente la de Lima, conocía el prospecto de un nuevo periódico: Mercurio Peruano. Con 411 números publicados hasta 1795, este periódico ha sido considerado el más importante del virreinato del Perú en el siglo XVIII, tanto por el alcance de su difusión - con suscriptores hasta en Nueva España, Nueva Granada, La Plata, Chile y España-, como por su impacto entre la comunidad letrada.

Sus editores y autores formaban parte de la élite peruana, educada en el contexto colonial por un sistema tradicional escolástico forjado a la luz del modelo universitario hispánico. Los años de circulación del periódico constituyeron un momento coyuntural y de tensiones entre la tradición cultural hispánica, el reformismo modernizador promovido por Carlos III y las aspiraciones ilustradas de las élites hispanoamericanas (Guibovich, 2005; Poupeney, 2009).

El periódico surgió como medio de expresión de la Sociedad de Amantes del País que congregaba a intelectuales admiradores de la Ilustración europea. Ellos, con seudónimos helénicos, tenían como finalidad promover la alta cultura en la sociedad colonial, adaptando este enfoque a temáticas de interés para el Perú. Así, el periódico versó sobre temáticas locales, historia, geografía, cultura y naturaleza peruanas, dejando menor espacio para noticias contingentes (Clément, 1990).

$\mathrm{Su}$ orientación permite reconocer al Mercurio Peruano, por una parte, como una plataforma de promoción del pensamiento ilustrado (Clément, 1983; Zeta, 2000; Guibovich, 2005; Solís, 2005; Ojeda, 2015; Poupeney, 2009). Por otra, el periódico ofrece un testimonio del ideario y bagaje cultural de quienes, años después, participarían de los procesos independentistas de las colonias hispanoamericanas. En tal sentido, la Sociedad de Amantes del País y el Mercurio Peruano constituyeron espacios de reconocimiento para la comunidad de letrados de la sociedad virreinal, sirviendo a la validación de su preeminencia social y cultural desde una perspectiva ilustrada.

Sin embargo, los principios de inspiración de este periódico no se agotan en las obras y autores modernos e iluministas. Sus letras traslucen explícitamente, con similar frecuencia e intensidad, el conocimiento y cultivo de la tradición clásica grecorromana por parte de autores, editores y de su comunidad de lectores. ¿Cuáles fueron los motivos y mecanismos que posibilitaron esta influencia?

Hernán Taboada (2014), por ejemplo, afirma que hasta el siglo XVIII no se desarrolló un estudio moderno de la Antigüedad en las colonias hispanoamericanas, y que este solo se habría canalizado hacia el siglo XIX, mediado por el Iluminismo. Alejandro Villalobos (2012) indica que los clásicos habrían llegado a los intelectuales criollos a través de traducciones realizadas por clérigos católicos, que no solo adaptaban el idioma, sino el contenido de los textos originales. Susana Gazmuri (2017), finalmente, afirma que los intelectuales que luego encabezarían los procesos de independencia parece que tuvieron conocimiento directo de algunos autores romanos, mientras que habrían conocido otras obras a través de la mediación de escritores franceses modernos.

El uso retórico de obras griegas y romanas en el Mercurio Peruano sugiere preguntas a las que, a lo largo de este artículo, esperamos atender. ¿Es tan relevante el lugar de la cultura clásica como el de la moderna Ilustración en este periódico? ¿Qué autores clásicos y qué conocimientos sobre ellos pudieron tener los autores y lectores del Mercurio Peruano? ¿Qué tipos de lectura y niveles de apropiación de la cultura y obras grecorromanas evidencian los autores peruanos en sus páginas? ¿Qué lugar ocuparon y qué rol ejercieron los clásicos en los textos contenidos en este periódico?

Nuestro objetivo consiste en analizar, desde la perspectiva de la historia de la lectura y de los estudios de recepción clásica (Martindale, 1993; Hardwick, 2003), los niveles de lectura y procesos de apropiación cultural de las obras clásicas en los textos contenidos en el Mercurio Peruano. Para ello, revisaremos las ediciones y obras que circularon en los ambientes libreros de Perú y, luego, aquellos que constituyeron referentes en dicho periódico, con el fin de comprender los niveles de conocimiento y cercanía que los intelectuales peruanos pudieron desarrollar sobre la literatura clásica. De esta manera será posible analizar los alcances de dicho conocimiento en la configuración de los discursos de la comunidad letrada que dialogó en torno al Mercurio Peruano.

Nuestra hipótesis sugiere que la presencia de la tradición clásica en este periódico puede comprender- 
se como el resultado de un proceso de recepción cultural, generado a partir de la transmisión, circulación y lectura de la literatura vinculada al mundo clásico antiguo por parte de la élite letrada de Perú, en tres distintos niveles: lectura directa, indirecta y mediada. La mención y alusión a obras y autores clásicos en el Mercurio Peruano denotan un bagaje cultural amplio y una comprensión compleja de los mismos por parte de los intelectuales peruanos, lectores activos que se apropiaron de discursos y conceptos de la literatura grecorromana como parte de sus propios imaginarios e idearios, y para la validación de los mismos.

Gracias a este conocimiento complejo y cercano sobre los clásicos, estos operaron como principios productores de sentido. Entonces, se constituyeron en códigos comunes y voces de autoridad entre la comunidad intelectual del virreinato para legitimar sus ideas en el entorno de sus pares hispanoamericanos y europeos, así como para fortalecer el sentido de pertenencia e identidad de dicha élite. Por medio de los clásicos, los temas locales podían abordarse más allá de su especificidad, anulando su particularidad americana e insertándose en la trama de la tradición europea occidental comprendida, a su vez, como una tradición universal.

\section{Los clásicos en los circuitos libreros del Perú virreinal}

Desde la consolidación de la presencia española en los dominios sudamericanos en el siglo XVI, la élite letrada del virreinato del Perú - la nobleza hispana y criolla, el clero y los funcionarios imperiales forjó un sentido de identidad sobre la base de sus vínculos culturales con el mundo transatlántico. Tanto su educación como sus aficiones literarias siguieron los modelos del Viejo Mundo, de manera que la literatura referida a asuntos locales fue proporcionalmente escasa en comparación con la bibliografía canónica, jurídica y literaria de origen europeo (Hampe, 1987; Leonard, 1942).

El afán por desarrollar en Perú una cultura a semejanza de España impulsó el crecimiento de bibliotecas privadas y de una red de circulación, importación y comercio de libros cuyos registros permiten advertir las huellas de la literatura clásica a la que los lectores peruanos pudieron acceder.
Las solicitudes de obras por parte de libreros para proveerse de mercancías dan cuenta de los títulos que podían ser de interés para sus potenciales clientes. Es el caso de Juan Jiménez del Río, quien, entre los libros que encargó en 1583 al presbítero Francisco de la Hoz, que viajaría a España, figuraban cuatro ejemplares de la Odisea, doce de la Eneida, veinticinco de Ovidio y cincuenta de las epístolas de Cicerón. Se agregaban, sobre el mundo antiguo, catorce ejemplares del Libro Áureo de Marco Aurelio de Antonio de Guevara, doce Summulae de Domingo de Soto - comentarista de la lógica aristotélica- y doce Commentaria unà cum quaestionibus, in uniuersam Aristotelis Logicam de Francisco de Toledo (Leonard, 1942).

De la lista anterior es posible observar que se disponía de ediciones de obras literarias latinas originales, mientras que las filosóficas - especialmente griegas - se transmitían mediante sumas o comentarios modernos del pensamiento antiguo. Dicha tendencia fue común en otros listados.

En carta fechada en 1591, el librero limeño Francisco Butrón se comprometía a pagar por un conjunto de libros. Entre ellos figuraban clásicos que, seguramente, se ofrecerían a la venta: seis ejemplares de las epístolas de Cicerón y siete de De Officiis, cuatro de Geórgicas de Virgilio y seis obras del mismo poeta en latín - sin especificar el título-, ocho de Heliodoro y cuatro Comedias de Terencio. Se sumaba además dos ejemplares de Principios de cirugía de Juan Fragoso, cuya obra se basaba en Galeno, a quien refiere constantemente, y en principios aristotélicos (Guibovich, 2019).

Estos listados sugieren que, entre los intereses de la sociedad letrada peruana, había espacio para la literatura antigua. La biblioteca del tesorero de la caja real de Lima, Antonio Dávalos, por ejemplo, registraba dos volúmenes de las Metamorfosis de Ovidio - con el título Las transformaciones-, los Anales de Tácito y las Sátiras de Persio en latín (Hampe, 1990).

A principios del siglo XVII, los inventarios de dos mercaderes españoles establecidos en Lima, así como algunas bibliotecas particulares de clérigos y funcionarios virreinales, registraban diversos autores y títulos de la Antigüedad. La librería de Cristóbal Hernández Galeas contenía veinte Comedias de Terencio 
- cuatro en latín -; tres ejemplares de Plinio, entre los que se especificaba un título De animales y uno De pescadores; dos de Julio César sin especificar, y uno en toscano titulado Comentarios — quizás, De bello gallico-; Ética y De anima de Aristóteles — seguramente, la primera traducida al español, la segunda en latín-, junto con un libro titulado Comentari in universa Aristotelis; De Oratore y cuatro Epístolas de Cicerón, además de otros tres libros del mismo autor sin título mencionado, uno de ellos en latín; Epístolas de Séneca y una obra sin título del mismo autor; un ejemplar de Marco Aurelio; uno de Quinto Curcio; Historias de Justino; Virgilio en latín y dos Fábulas de Esopo (González, 1997).

En tanto, la librería de Pedro Durango, inventariada en 1603, tenía un ejemplar de Comentarios de Aristóteles, Proverbios de Séneca en romance, una obra de Julio César sin especificar, tres ejemplares de República de Aristóteles - es decir, Política-, cuatro Farsalia de Lucano, uno de Ovidio comentado, uno de Apiano alejandrino y dos Fábulas de Esopo (González, 1996).
Ovidio, Plinio, Terencio, Tácito, Fedro y Quintiliano. Dávalos tenía, además, obras de Galeno, Hipócrates, Celso y Euclides, y Concha, libros de Isócrates, Demóstenes, Epicteto, Aristófanes, Apiano, Petronio, Pausanias, Pompeyo Trogo, Quinto Curcio y Tertuliano, ello a principios del siglo XIX (Willen, 1956).

La biblioteca del jesuita Miguel de León, inventariada en Lima en 1767, registraba ejemplares de Catulo, Quinto Curcio Rufo, Ovidio, Claudiano, Tibulo, Propercio, Plauto, quince ejemplares de Cicerón, doce de Virgilio. Además, contaba con los veintiún volúmenes de Historia Romana de Catrou y diecinueve de Historia Antigua de Rollin (Burga, 1969).

Los inventarios de bienes de difuntos de los inmigrantes españoles en Perú ratifican las tendencias de lectura en materias de clásicos y latinidad. Aproximadamente, un tercio de los libros inventariados entre los siglos XVI y XVII en Lima constituyeron obras de gramática, entre las que destacaban la de Antonio de Nebrija y su Dictionarium latino-hispanicum, el Dictionarium vocibus latinis Italicae, Gallicae et His-

\section{Por medio de los clásicos, los temas locales podían abordarse más allá de su especifi- cidad, anulando su particularidad americana e insertándose en la trama de la tradición europea occidental.}

No solo en Lima se han conservado registros de obras clásicas. En Cusco, la biblioteca de Agustín Valenciano de Quiñones, inventariada en 1576, guardaba Ética de Aristóteles, Retórica de Cicerón, una obra de Platón, una de Ovidio, Noches Áticas de Aulio Gelio, Vidas paralelas de Plutarco, Historia Natural de Plinio, Décadas de Tito Livio en latín y Diodoro Sículo (Hampe, 1996). En 1670, la biblioteca de Alonso Bravo de Paredes registraba un ejemplar de Valerio Máximo, Flavio Josefo, Juvenal, Persio y Quinto Curcio, dos de Virgilio - uno en romance - y uno de Justo Lipsio — quizás, su traducción de Séneca(Cisneros y Guibovich, 1982).

Para el siglo XVIII y comienzos del XIX, algunas bibliotecas de la sociedad limeña continuaron esta tendencia. José Manuel Dávalos y José de Santiago Concha y Traslaviña poseían obras de Cicerón, César, Homero, Horacio, Lucano, Juvenal, Plutarco, Virgilio, paniae de Ambrosiu Calepini y el título Libro de la lengua latina.

En medicina, el más frecuente era Principios de cirugía de Juan Fragoso, seguido de Aforismos de Hipócrates y De locis manifeste pugnantibus apud Galenum libellus de Francisco Valles de Covarrubias. En literatura, lideraba Virgilio, seguido por las epístolas y De Officiis de Cicerón, así como por Juvenal, Terencio, Horacio, Suetonio, Aulo Gelio y Lucio Anneo Floro. Finalmente, en filosofía, los comentarios sobre Aristóteles y Platón eran los más recurrentes (González, 1997).

Si bien las prácticas de lectura variaron a lo largo de las tres centurias coloniales, la presencia de los autores clásicos fue relativamente constante. Una revisión panorámica de los inventarios señalados permite advertir la prevalencia de obras latinas por sobre 
las helénicas. Entre estas últimas destacan Homero, Diodoro Sículo, Plutarco y Platón. En el caso latino, las existencias bibliográficas más frecuentes eran las literarias, historiográficas y filosóficas, en especial del siglo I a. C. Entre ellas, las de Ovidio, Virgilio, Cicerón, Tito Livio, Séneca y Terencio (Hampe, 1987).

Los textos de carácter científico, en cambio, correspondían a obras modernas que recogían, en latín, los contenidos del pensamiento antiguo, como los de Galeno e Hipócrates; además de la obra de Fragoso, así ocurría con Opúsculo de Astrología en Medicina, de Juan de Figueroa (Lima, 1660), con referencias a Galeno, Hipócrates, Aristóteles y Ptolomeo (Medina, 1966).

Igualmente, a lo largo de estos siglos, se observa una variedad de traducciones al romance o castellano, que incorporaban comentarios de editores modernos. Otras mantenían el latín, sobre todo las literarias. Las obras griegas fueron frecuentemente objeto de traducciones latinas.

\section{Clásicos para la educación de la élite letrada del Perú}

La existencia de obras clásicas en bibliotecas y librerías no constituye plena garantía de su lectura. Son las prácticas e instancias que posibilitaron la aproximación de los lectores a ellas lo que permite concebir que en el Perú colonial se haya desarrollado una vinculación dialógica entre la élite letrada y los autores antiguos a través de la lectura, estudio y difusión de sus obras.

Ello fue posible en el contexto de un sistema escolar y universitario que, siguiendo el modelo de enseñanza europeo, estableció para la instrucción de la élite niveles de educación sobre la base de los estudios de latinidad y de una metodología escolástica. En este marco, la influencia de la orden jesuita en los territorios americanos fue decisiva, organizando el sistema de colegios y universidades en Perú a partir de las orientaciones formuladas por la Ratio Studiorum (Guibovich, 2019).

La formación contemplaba ciclos de estudios inferiores y superiores. El primero se iniciaba con Gramática latina, para pasar a Humanidades y a una cátedra final de Elocuencia. El segundo nivel de Gra- mática incluía la lectura y traducción de las epístolas de Cicerón y los poemas de Ovidio. En el siguiente, se agregaban églogas de Virgilio y fragmentos de Catulo, Tibulo y Propercio. La clase de Humanidades sugería la lectura y explicación de Pro lege Manilia, Pro Archia y Pro Marcelo de Cicerón, fragmentos de la Eneida, de César, Salustio, Tito Livio, Quinto Curcio, Horacio, y epigramas y elegías latinos. Elocuencia, finalmente, contemplaba a Cicerón.

Los estudios superiores disponían de tres años de Filosofia, donde se abarcaba a autores como Aristóteles para Matemáticas, Física y Ética. La educación podía cumplir con un último nivel de Teología, basada en la lectura de textos en latín (BNP, 1951). Un elogio a un médico graduado por la Real Universidad de San Marcos de Lima, en 1791, recordaba parte de las lecturas realizadas por el egresado a lo largo de su formación: Cicerón para aprender latín, Demóstenes para el griego, Aristóteles para filosofía, Euclides para matemáticas (Mercurio Peruano, t. II, n. ${ }^{\circ}$ 54, 10 de julio de 1791, f. 183).

Las Propositiones de retórica, filosofía, matemáticas y astronomía presentadas por los estudiantes universitarios confirman este canon de lecturas. Los estudiantes exponían en latín, basándose en autores abordados en las cátedras, como Aristóteles, Cicerón, Séneca, Virgilio, Ovidio y Horacio. No obstante, para estas lecturas se requería la selección de ediciones. Tratándose de textos paganos, sus versiones debían estar exentas de principios que atentaran contra el credo cristiano (Ratio Studiorum, 1635, p. 388; Vásquez, 1999).

Así, parte de la filosofía aristotélica se abordaba mediante los comentarios de Duns Scoto, cuya obra fue una de las primeras impresas en Lima, en 1610, por Jerónimo Varela, con el título Commentarii ac quaestiones in universam Aristotelis ac subtilissimi Doctoris Ihoannis Duns Scoti logicam (Medina, 1966; Rivera de Tuesta, 1999). En 1694 se publicó, también en Lima, una Summa tripartita scholasticae, philosophae sive cursus philosophicus triennalis, in logicam, physicam et metaphysicam Aristotelis, por Nicolás de Olea (Medina, 1966).

La obra de Tito Livio, que llegó al Nuevo Mundo en el siglo XVII, solía leerse con los comentarios 
de Justo Lipsio, y los textos de retórica de Aristóteles y Quintiliano eran estudiados a través de De arte rhetorica libri tres ex Aristotele, Cicerone et Quintiliano de Cipriano Suárez (Osorio, 1980). En tal sentido, la lectura era guiada según claves de interpretación que definían los comentaristas y transcriptores, representantes de la cultura canónica, resultando de ello una lectura mediada.

Hacia la segunda mitad del siglo XVIII, período de formación de los intelectuales que participaron en el Mercurio Peruano, el cultivo de los clásicos seguía constituyendo un eje articulador de la educación de la élite. Ello explica que, en 1770, el presbítero Juan José Legarda haya publicado en Lima una nueva edición de la Ilustración de Nebrija, como método para aprender latín (Medina, 1966). Lo mismo se reflejaba en Instrucción de la lengua latina o Arte de adquirirla por la traducción de los autores, compuesta para la particular enseñanza de unos niños, del clérigo Esteban de Orellana, publicado en Lima en 1759. En esta obra, el autor proponía un método para enseñar latín en las escuelas peruanas que se apoyaba en el conocimiento progresivo de autores: sugería comenzar por Fedro, Sulpicio Severo, Eutropio, Cornelio Nepote, Veleyo Patérculo, Aurelio Víctor y las epístolas de Cicerón. Más complejos consideraba a Virgilio y Salustio.

En lugares selectos de autores latinos de prosa más excelentes para exercicio de la traducción (1760), el mismo autor detallaba el aporte de cada escritor romano para aprender latín: Catón, Cicerón, César, Tácito, Tito Livio, Séneca, Plinio, Justino, Aurelio Víctor, Aulio Gelio, Lactancio, Veleyo Patérculo, Valerio Máximo, Suetonio, Macrobio, Salustio y Virgilio. Sus comentarios demuestran que Orellana conocía un vasto catálogo de autores, aun cuando lamentaba que en Perú existiesen pocas ediciones latinas. Ante eso, sugería estudiar con el texto Latini Sermonis Exemplaria: E Scriptoribus Probatissimis, cuya existencia, seguramente, era más frecuente que la de las fuentes romanas o sus traducciones (Orellana, 1759; Orellana, 1760).

Este panorama permite inferir que la aproximación a obras clásicas por parte de la sociedad letrada peruana fue constante a lo largo del período colonial, aun cuando los modos de interpretación e interés pudieron variar. Una historia de la lectura no considera solo el registro material de libros, sino sus lecturas, interpretaciones y reescrituras. Justamente, el Mercurio Peruano es una fuente valiosa para conocer la proximidad de los intelectuales peruanos con los clásicos a fines del siglo XVIII. Su condición de autores se construye a partir de su índole previa de lectores activos, en el marco de una formación estructurada a partir de la valoración y cultivo de la cultura clásica.

\section{Lecturas y aproximaciones a los clási- cos antiguos desde el Mercurio Peruano}

La mención, alusión o referencia a obras y autores clásicos son constantes en el Mercurio Peruano. En sus páginas es posible observar un conocimiento de los textos antiguos a través de tres categorías de lectura o modos de aproximación: directa, indirecta y mediada. Mediante ellas, será posible distinguir los autores y materias que los intelectuales pudieron conocer de primera fuente y los que habrían llegado a constituir parte de su bagaje cultural, filtradas por los ojos del mundo moderno.

Si descartamos que los lectores americanos a fines del siglo XVIII hayan podido acceder a los manuscritos originales del mundo antiguo, entenderemos por lectura directa aquella que se realizaba sobre documentos en su lengua original, latín o griego. Si bien contenidas en ediciones modernas, se trataría de versiones respetuosas del texto antiguo, lo que daba al lector la posibilidad de dotar por sí mismo de sentido a los discursos expuestos por el autor original (Fischer, 2004).

Asimismo, lectura indirecta se considerará el acceso a textos antiguos a través de textos modernos cuyos autores realizaron un ejercicio de selección, interpretación o manipulación del contenido, apoyándose explícita o implícitamente sobre una fuente para transmitir sus propias ideas o conclusiones. En algunos casos, se percibe en el libro moderno un vínculo de intertextualidad con las obras antiguas (Barei, 2019).

Finalmente, lectura mediada será aquella traducida al español u otra lengua romance -o bien, del griego al latín-, cuyo propósito es ofrecer un texto 
comentado o interpretado por un autor moderno para un lector contemporáneo, lo que implica adaptaciones de su contenido. Supone, por tanto, que el acercamiento al libro por parte del lector se produce a través de un mediador que sugiere o dispone los sentidos que deben hallarse en el texto original (Fischer, 2004).

\subsection{Lecturas directas de las obras clásicas}

Resulta complejo identificar con certeza una aproximación directa de los autores peruanos a un texto antiguo. Aun respetando su lengua original, la fuente material utilizada fue siempre una edición moderna, cuyo ejercicio paleográfico y morfosintáctico, así como la disposición del texto, pueden haber alterado la interpretación de sus sentidos. Con todo, el esfuerzo de los redactores del Mercurio Peruano por incorporar citas textuales de fuentes clásicas da cuenta del reconocimiento de su autoridad y de una voluntad de los modernos por identificarse con los intelectuales antiguos, en una línea directa de continuidad de pensamiento.

En tal sentido, es sugerente el artículo "Apólogo histórico sobre la corrupción de las colonias romanas de África”, publicado en el quinto número del Mercurio Peruano, el 16 de enero de 1791. Su autor, Hesperiófilo - seudónimo de José Rossi y Rubí-, comienza declarando que la historia es materia predilecta del periódico, por lo que la Sociedad de Amantes del País se esforzó por comprar una gran cantidad de manuscritos. Entre ellos se habrían encontrado "un pergamino medio carcomido, que no sabemos si es de Tácito, de Floro, ó de Suetonio" (MP, t. II, n. ${ }^{\circ} 42,26$ de mayo de 1791, f. 33), titulado con el mismo nombre que el artículo publicado, con un exordio y sin final. Sin indicar su idioma, puede suponerse que sería un texto en latín, el que Hesperiófilo se habría dispuesto a traducir y transcribir para el periódico.

La transcripción se inicia con una cita a Sátiras I.1.69 de Horacio: Quid rides? Mutato nomine de te fabula narratur. Se sigue de la supuesta traducción del texto, referido a la degradación moral de los colonos romanos en África, quienes, expuestos a los lujos obtenidos por la expansión de su patria, habían olvidado el rigor y virtud de sus orígenes. El texto romano original no existe o, al menos, no tenemos conocimien- to de un documento similar. La transcripción no es tal, sino un texto de autoría de Hesperiófilo, quien, alegóricamente, criticaba la moralidad de la sociedad peruana de su tiempo. Lo sugiere así con la cita escogida de Horacio, que refiere a no reír del otro cuando la broma puede versar sobre uno mismo. Y lo indica también cuando, al introducir el texto, afirma que el hallazgo del pergamino había coincidido con el momento cuando discutían sobre la necesidad de escribir una historia de la moral pública peruana.

No se trata, en este caso, de la lectura directa de una fuente romana antigua, pero sí de un pretexto que sugiere el lugar que los clásicos ocupaban como voces de autoridad y punto de referencia para establecer un patrón de identificación con ellos. La cita de Horacio, en cambio, parece provenir de una lectura directa que no era inusual: tanto este como otros escritores romanos, mayoritariamente de los siglos I a. C. y I d. C., fueron frecuentemente citados en latín y constituyeron la fuente más recurrente de aproximación directa entre los intelectuales peruanos.

La lectura de las obras de Horacio parece haber sido directa. Versos de sus Sátiras (MP, t. II, n. ${ }^{\circ} 36,5$ de mayo de 1791, f. 62; MP, t. IV, n. ${ }^{\circ} 104$, 1 de enero de 1792, f. 1; MP, t. IV, n. ${ }^{\circ} 136,22$ de abril de 1792 , f. 275; MP, t. VI, n. ${ }^{\circ} 201,6$ de diciembre de 1792 , f. 235), de sus Odas (MP, t. II, n. ${ }^{\circ}$ 58, 24 de julio de 1791, f. 224; MP, t. VI, n. ${ }^{\circ} 178,16$ de septiembre de 1792, f. 40) y de las Epístolas (MP, t. III, n. ${ }^{\circ} 73,15$ de septiembre de 1971, f. 36; MP, t. VII, n. ${ }^{\circ} 222$, 17 de febrero de 1793, f. 119) son citados en latín.

$\mathrm{Su}$ Oda III.24 se publicó traducida por un colaborador, Bernardino Ruiz, quien habla del romano como el "divino lírico" (MP, t. I, n. ${ }^{\circ} 15,20$ de febrero de 1791, f. 138). Algunos números después, los editores del Mercurio Peruano indicaban que esta colaboración había tenido buena recepción entre los lectores (MP, t. I, n. ${ }^{\circ}$ 25, 27 de marzo de 1791, f. 236). Quizás por este motivo, luego se publicaron las Odas I.3 en español, con algunos comentarios sobre el ejercicio de su traducción (MP, t. III, n. ${ }^{\circ}$ 69, 1 de septiembre de 1791, ff. 323[6]- 325[8]), y Odas II.10 (MP, t. VIII, n. ${ }^{\circ} 275,22$ de agosto de 1793, ff. 270-271).

Por supuesto, las citas latinas a Ars Poetica tampoco faltaron (MP, t. II, n. ${ }^{\circ}$ 58, 24 de julio de 1791, ff. 
224-225; MP, t. III, n. ${ }^{\circ}$ 77, 29 de septiembre de 1791, f. 68; MP, t. VI, n. ${ }^{\circ} 199,29$ de noviembre de 1792, f. 215; MP, t. VII, n. ${ }^{\circ}$ 209, 3 de enero de 1793, f. 1; MP, t. VII, n. ${ }^{\circ} 224,24$ de febrero de 1793, f. 138; MP, t. VIII, n. ${ }^{\circ}$ 255, 13 de junio de 1793, f. 102). Horacio - llamado "maestro" - fue, junto con Virgilio y Cicerón, el escritor romano más frecuentemente citado en el Mercurio Peruano.

Horacio había inspirado, a fines del siglo XVII, al poeta peruano Juan Caviedes, cuyos versos fueron publicados en el periódico, antecedidos por la cita de Epistola ad Pisones 139, parturient montes, nascetur ridiculus mus [Parirán los montes y nacerá un ridículo ratón], quizás jugando con el contraste entre el mundano motivo del poema y la grandilocuencia de su estilo (MP, t. I, n. ${ }^{\circ}$ 34, 28 de abril de 1791, f. 313).

Las obras latinas que parecen citadas directamente en el Mercurio Peruano con referencias bibliográficas correspondientes a su organización original fueron numerosas. Así tenemos:

- Quintiliano, Institutio Oratoria de (t. I, n. ${ }^{\circ} 18$, 3 de marzo de 1791, f. 159).

- Tácito, Annales (t. IV, n. ${ }^{\circ}$ 119, 23 de febrero de 1793, f. 125).

\section{Los artículos del periódico demuestran que el conocimiento de dicha comunidad sobre los clásicos fue amplia y variada, y alcanzó un nivel de inteligibilidad activa que permitió a los intelectuales peruanos apropiarse de las letras antiguas.}

- Cicerón, De Officiis (t. II, n. ${ }^{\circ} 36,5$ de mayo de 1791, f. 10; t. IV, n. ${ }^{\circ} 119,23$ de febrero de 1792, f. 128; t. IV, n. ${ }^{\circ} 121,1$ de marzo de 1792 , f. 147), De Legibus (t. II, n. ${ }^{\circ}$ 42, 26 de mayo de 1791 , f. 61 ; t. IV, n. ${ }^{\circ} 116,12$ de febrero de 1792, f. 101), De Oratore (t. VII, n. ${ }^{\circ} 209,3$ de enero de 1793, f. 8), De amicitia (t. VIII, n. ${ }^{\circ}$ 243, 2 de mayo de 1793, f. 2), De finibus bonorum et malorum (t. VII, n. ${ }^{\circ} 220,10$ de febrero de 1793, f. 103; t. VII, n. ${ }^{\circ} 222,17$ de febrero de 1793, f. 127), Somnium Scipionis (t. VIII, n. ${ }^{\circ}$ 272, 11 de agosto de 1793, f. 244), Tusculanae Disputationes (t. II, n. ${ }^{\circ}$ 57, 21 de julio de 1791, f. 210; t. III, n. ${ }^{\circ} 91,17$ de noviembre de 1791, f. 199), Epistolas (t. VII, n. ${ }^{\circ} 222,17$ de febrero de 1791, f. 127), Catilinarias (t. VIII, n. ${ }^{\circ} 255$, 13 de junio de 1793, f. 102), Pro Murena (t.
IV, n. ${ }^{\circ} 120,26$ de febrero de 1792, f. 136), Pro Ligario (t. IV, n. ${ }^{\circ} 120,26$ de febrero de 1792, f. 137) y Lucullus (t. VII, n. ${ }^{\circ} 221,14$ de febrero de 1793, f. 113).

- Aulio Gelio, Noches áticas (t. II, n. ${ }^{\circ}$ 36, 5 de mayo de 1791, f. 13).

- Juvenal, Sátiras (t. II, n. ${ }^{\circ}$ 37, 8 de mayo de 1791, f. 17 ; t. III, n. ${ }^{\circ} 98,11$ de diciembre de 1791, f. 261; t. IV, n. ${ }^{\circ} 111,26$ de enero de 1792, f. 64; t. IV, n. ${ }^{\circ} 135,19$ de abril de 1792, ff. 269-270).

- Séneca, De Beneficiis (t. IV, n. ${ }^{\circ} 119,23$ de febrero de 1792, f. 128; t. VI, n. ${ }^{\circ} 201,6$ de diciembre de 1792, f. 237).

- Petronio, Satiricón (t. III, n. ${ }^{\circ}$ 79, 6 de octubre de 1791, f. 84).

- Persio, Sátiras (t. III, n. ${ }^{\circ}$ 84, 23 de octubre de 1791, f. 141; t. III, n. ${ }^{\circ} 97,8$ de diciembre de 1791; t. X, n. ${ }^{\circ} 319,23$ de enero de 1794).

- Lucrecio, De rerum natura (t. III, n. ${ }^{\circ} 92,20$ de noviembre de 1791, f. 215; t. IV, n. ${ }^{\circ} 113,2$ de febrero de 1792, ff. 78-79; t. VIII, n. ${ }^{\circ} 278,31$ de agosto de 1793, f. 297).

- Suetonio, Doce Césares (t. III, n. ${ }^{\circ} 79,6$ de octubre de 1791, f. 84).

- Plutarco, Moralia (t. IV, n. ${ }^{\circ} 106,8$ de enero de
1792, f. 24).

- Ovidio, Metamorphoseis (t. II, n. ${ }^{\circ} 62,7$ de agosto de 1791, f. 250; t. V, n. ${ }^{\circ} 167,9$ de agosto de 1792, f. 232; t. VI, n. ${ }^{\circ} 207,27$ de diciembre de 1792, f. 287; t. VII, n. ${ }^{\circ} 220,10$ de febrero de 1793 , ff. 101 y 104), Fastos (t. III, n. ${ }^{\circ} 79,6$ de octubre de 1791, f. 85; t. III, n. ${ }^{\circ} 82,16$ de octubre de 1791, f. 12; t. IV, n. ${ }^{\circ} 138,29$ de abril de 1792, f. 297; t. XI, n. ${ }^{\circ} 378,17$ de agosto de 1794, f. 252), Tristes (t. IV, n. ${ }^{\circ} 111,26$ de enero de 1792, f. 64), Remedia amoris (t. IV, n. ${ }^{\circ} 122$, 4 de marzo de 1792, f. 153; t. VII, n. ${ }^{\circ} 220,10$ de febrero de 1793, f. 100; t. VIII, n. ${ }^{\circ} 245,9$ de mayo de 1793, ff. 17 y 20) y Ex Ponto (t. V, n. ${ }^{\circ}$ 170, 19 de agosto de 1792, f. 255; t. III, n. ${ }^{\circ} 72$, 11 de septiembre de 1791, f. 32).

- Virgilio, Geórgicas (t. V, n. ${ }^{\circ}$ 147, 31 de mayo de 
1792, f. 69; t. XI, n. ${ }^{\circ}$ 373, 31 de julio de 1794, f. 217), Bucólicas (t. III, n. ${ }^{\circ}$ 78, 2 de octubre de 1791, f. 78; t. VIII, n. ${ }^{\circ}$ 246, 12 de mayo de 1793, f. 27) y Eneida (t. III, n. ${ }^{\circ} 79,6$ de octubre de 1791, f. 83; t. III, n. ${ }^{\circ} 99,15$ de diciembre de 1791, f. 269; t. IV, n. ${ }^{\circ} 111,26$ de enero de 1792, ff. 64 y 66 ; t. IV, n. ${ }^{\circ} 120,26$ de febrero de 1792, f. 136; t. IV, n. ${ }^{\circ} 125,15$ de marzo de 1792, f. 185; t. V, n. ${ }^{\circ} 167,9$ de agosto de 1792 , f. 231 ; t. $\mathrm{V}$, n. $^{\circ} 170,19$ de agosto de 1792 , f. 256; t. VI, n. ${ }^{\circ} 191,1$ de noviembre de 1792 , f. 144; t. VII, n. ${ }^{\circ} 218,3$ de marzo de 1793, f. 85; t. VIII, n. ${ }^{\circ}$ 257, 20 de junio de 1793, f. 121; t. XI, n. ${ }^{\circ} 348,4$ de mayo de 1794 , f. 9; t. XI, n. ${ }^{\circ}$ 354, 25 de mayo de 1794, f. 63; t. XI, n. ${ }^{\circ} 379$, 21 de agosto de 1794, f. 260).

- Marcial, Epigramas (t. IV, n. ${ }^{\circ} 125,15$ de marzo de 1792, f. 182; t. VIII, n. ${ }^{\circ} 255,13$ de junio de 1793, f. 101).

- Catulo, Carmina (t. IV, n. ${ }^{\circ} 122,4$ de marzo de 1792, f. 153).

- Plauto, Trinummus (t. IV, n. ${ }^{\circ} 120,26$ de febrero de 1792, f. 133).

- Plinio, Historia natural (t. IV, n. ${ }^{\circ} 115,9$ de febrero de 1792, f. 97; t. IV, n. ${ }^{\circ} 116,12$ de febrero de 1792, ff. 100-101; t. IV, n. ${ }^{\circ} 119,23$ de febrero de 1792, f. 128; t. IV, n. ${ }^{\circ} 125,15$ de marzo de 1792, f. 189; t. VII, n. ${ }^{\circ} 221,14$ de febrero de 1793, f. 116; t. XI, n. ${ }^{\circ} 372,27$ de julio de 1794, ff. 206 y 209).

- Catón, De Re Rustica (t. VII, n. ${ }^{\circ} 222,17$ de febrero de 1793, f. 118).

- Terencio, Comedias (t. VIII, n. ${ }^{\circ} 246,12$ de mayo de 1793, f. 34).

- Frontino, De aquaeductu urbis Romae (t. IV, n. ${ }^{\circ} 115,9$ de febrero de 1792, f. 98).

- Lucano, Farsalia (t. IV, n. ${ }^{\circ} 113,2$ de febrero de 1792, ff. 78-79; t. IV, n. ${ }^{\circ} 114,5$ de febrero de 1792, f. 88; t. IV, n. ${ }^{\circ} 120,26$ de febrero de 1792, f. 133; t. V, n. ${ }^{\circ} 161,19$ de julio de 1792 , f. 182).

- Galeno, De Anatomicis Administrationibus (t. VII, n. ${ }^{\circ} 221,14$ de febrero de 1793, f. 111; t. VII, n. ${ }^{\circ} 222,17$ de febrero de 1793, f. 119).

Ab urbe condita de Tito Livio también es citada, aunque sus frases pudieron haber sido leídas en otros textos históricos o jurídicos, como la cita fons omnis publici privatique iuris [fuente de todo el derecho público y privado] (Ab urbe condita III.34.6, en MP, t. I, n. ${ }^{\circ} 15,20$ de febrero de 1791, f. 134), para definir la importancia de las Doce Tablas. Lo mismo ocurre con la máxima communis utilitas, quæ societatis maximum vinculum est [la utilidad común es el máximo vínculo de la sociedad] (XXXVI.7, en MP, t. I, n. ${ }^{\circ}$ 34, 28 de abril de 1791, f. 307), que formaba parte de compilaciones de frases célebres del historiador romano, o con las palabras de Quinto Capitolino (MP, t. VI, n. ${ }^{\circ}$ 198, 25 de noviembre de 1792, f. 212), recogidas también en obras como Coleccion de las partes mas selectas de los mejores autores de pura latinidad de Pablo Lozano (Madrid, 1777).

Similar es el caso de una cita a De morbus chronicorum de Celio Aureliano. Aunque puede tratarse de una transcripción directa, la oración se registraba en tratados del siglo XVIII. De ser así, se trataría de una lectura mediada, aun cuando se presenta como referencia de una lectura directa.

La mayoría de estas citas se utilizaba como fundamento de afirmaciones o máximas para avalar los planteamientos de los autores modernos. Algo similar ocurre con las sentencias morales de Dionisio Catón contenidas en Catonis Disticha, obra que desde tiempos medievales constituyó un texto común para la educación moral. Sus oraciones debieron ser objeto de conocimiento directo de los intelectuales peruanos a través de ediciones modernas, como las de Desiderio Erasmo (1533) y Antonio de Nebrija (1553), comentadores sobre quienes el Mercurio Peruano no hace referencia (MP, t. II, n. ${ }^{\circ}$ 50, 23 de junio de 1791, f. 133).

A la compilación que sí refiere es a una edición de Londres de un Corpus Poetarum (MP, t. II, n. ${ }^{\circ}$ 2, 3 de julio de 1791, ff. 153-155) que incluía los versos de Décimo Laberio recogidos en Saturnales II.7 de Macrobio, citados en latín y traducidos por un poeta de seudónimo Nerdacio.

En otras situaciones, la cita se asociaba a un autor, pero la referencia no se explicitaba. Podría inferirse que la obra era de conocimiento común o que la máxima citada era conocida a través de textos compilatorios. Así ocurre con Salus publica suprema lex esto 
[La salud del pueblo es ley suprema] (De leg., III, 3, 8; en MP, t. III, n. ${ }^{\circ}$ 103, 29 de diciembre de 1791, f. 308), Omnia pontus erat [Todo era mar] (Met. I.292; en MP, t. IV, n. ${ }^{\circ} 106,8$ de enero de 1792, f. 24), con una frase de De militari disciplina de Vegetius (MP, t. IV, n. ${ }^{\circ} 106,8$ de enero de 1792, f. 21), un verso de la Eneida (MP, t. XI, n. ${ }^{\circ}$ 372, 27 de julio de 1794, f. 208) y una cita a Bellum Iugurthinum de Salustio (MP, t. II, n. ${ }^{\circ}$ 55, 14 de julio de 1791, f. 188 ), recogida en libros como Opusculos de oro: virtudes morales christianas de Luis Calderón (Madrid, 1707).

Solo una cita se registra directamente en griego, aunque con caligrafía latina: se trata del verso VII.99 de la Ilíada, que se sigue de su traducción al español (MP, t. II, n. ${ }^{\circ}$ 65, 18 de agosto de 1791, f. 285), quizás asumiéndose que pocos lectores podrían entenderla en su lengua original.

En otros casos no se utilizaban citas explícitas, pero sí paráfrasis que se acompañaban de referencias específicas al texto antiguo en notas a pie de página, lo que sugiere que los autores peruanos pudieron conocer directamente la fuente: a los romanos, en lengua latina, y a los griegos, en cambio, traducidos probablemente al latín. El catálogo de obras referidas en el Mercurio Peruano, en este caso, es variado y numeroso:

- Diodoro Sículo, Biblioteca Histórica (t. I, n. ${ }^{\circ}$ 6, 20 de enero de 1791, f. 41; t. VII, n. ${ }^{\circ} 221,14$ de febrero de 1793, f. 116).

- Columela, De re rustica (t. I, n. ${ }^{\circ}$ 6, 20 de enero de 1791, f. 41).

- Herodiano, Historia Romana (t. I, n. ${ }^{\circ}$ 6, 20 de enero de 1791, f. 41).

- Dionisio de Halicarnaso, Antiquitates Romanae (t. I, n. ${ }^{\circ} 12$, 10 de febrero de 1791, f. 109).

- Plinio, Historia natural (t. I, n. ${ }^{\circ} 12,10$ de febrero de 1791, f. 109; t. II, n. ${ }^{\circ}$ 59, 28 de julio de 1791, f. 228; t. III, n. ${ }^{\circ} 102$, 25 de diciembre de 1791, f. 293; t. IV, n. ${ }^{\circ} 110,22$ de enero de 1792, f. 55; t. IV, n. ${ }^{\circ} 111,26$ de enero de 1792 , f. 65 ; t. V, n. ${ }^{\circ} 161,19$ de julio de 1792, f. 181 ; t. V, n. ${ }^{\circ} 167,9$ de agosto de 1792, f. 232; t. VII, n. ${ }^{\circ} 222,17$ de febrero de 1793, f. 119; t. IX, n. ${ }^{\circ}$ 282, 15 de septiembre de 1793, f. 30).

- Aristóteles, Poética (t. I, n. ${ }^{\circ}$ 16, 24 de febrero de 1791, f. 144).
- Cicerón, Pro Archia (t. I, n. ${ }^{\circ}$ 18, 3 de marzo de 1791, f. 157; t. IV, n. ${ }^{\circ} 104$, 1 de enero de 1792, f. 4), Tusculanae Disputationes (t. II, n. ${ }^{\circ}$ 52, 3 de julio de 1791, f. 153; t. II, n. ${ }^{\circ}$ 57, 21 de julio de 1791, f. 214; t. III, n. ${ }^{\circ} 83,20$ de octubre de 1791, f. 132), Pro Murena (t. III, n. ${ }^{\circ}$ 83, 20 de octubre de 1.791, f. 132), De Officiis (t. III, n. ${ }^{\circ}$ 84, 23 de octubre de 1791, f. 141; t. IV, n. ${ }^{\circ} 120,26$ de febrero de 1792, f. 138) y De Oratore (t. II, n. ${ }^{\circ}$ 55, 14 de julio de 1791, f. 188; t. III, n. ${ }^{\circ} 83$, 20 de octubre de 1791, f. 133).

- Lucrecio, De rerum natura (t. I, n. ${ }^{\circ} 22,17$ de marzo de 1791, f. 202; t. III, n. ${ }^{\circ} 75,22$ de septiembre de 1791, f. 56).

- Estrabón, Geografía (t. I, n. ${ }^{\circ}$ 25, 27 de febrero de 1791, f. 235; t. III, n. ${ }^{\circ} 79,6$ de octubre de 1791, f. 85; t. IV, n. ${ }^{\circ} 115,9$ de febrero de 1792 , f. 97).

- Platón, La República (t. II, n. ${ }^{\circ}$ 52, 3 de julio de 1791, f. 153; t. III, n. ${ }^{\circ}$ 83, 20 de octubre de 1791, f. 135) y Las Leyes (t. IV, n. ${ }^{\circ} 123,8$ de marzo de 1792, f. 156; t. IV, n. ${ }^{\circ} 125,15$ de marzo de 1792, f. 172).

- Heródoto, Historia (t. III, n. ${ }^{\circ}$ 79, 6 de octubre de 1791, ff. 84-85; t. V, n. ${ }^{\circ} 161,19$ de julio de 1792, f. 181).

- Marcial, Epigramas (t. III, n. ${ }^{\circ} 73,15$ de septiembre de 1791 , f. 40 ; t. V, n. ${ }^{\circ} 167,9$ de agosto de 1792, f. 232).

- Tácito, Germania (t. III, n. ${ }^{\circ}$ 79, 6 de octubre de 1791, f. 86).

- Horacio, Odas (t. III, n. ${ }^{\circ}$ 94, 27 de noviembre de 1791, f. 232).

- Aristófanes, Pluto (t. XI, n. ${ }^{\circ}$ 373, 31 de mayo de 1794, f. 223).

- Cornelio Nepote, De viris illustribus (t. III, n. ${ }^{\circ}$ 83, 20 de octubre de 1791, f. 132).

- Salustio, De Catilinae coniuratione (t. III, n. ${ }^{\circ}$ 83, 20 de octubre de 1791, f. 132; t. IV, n. ${ }^{\circ}$ 122, 4 de marzo de 1792, f. 153).

- Polibio, Historia (t. III, n. ${ }^{\circ}$ 83, 20 de octubre de 1791, f. 133).

- Plutarco, Moralia (t. III, n. ${ }^{\circ}$ 83, 20 de octubre de 1791, ff. 133 y 136; t. III, n. ${ }^{\circ} 91,17$ de noviembre de 1791, f. 196) y Vidas Paralelas (t. IV, n. ${ }^{\circ} 120,26$ de febrero de 1792, f. 138). 
- Tito Livio, Décadas (t. IV, n. ${ }^{\circ} 125,15$ de marzo de 1792, f. 186).

- Quintiliano, Institutio Oratoria (t. III, n. ${ }^{\circ} 83$, 20 de octubre de 1791, f. 133).

- Macrobio, Saturnalia (t. III, n. ${ }^{\circ}$ 83, 20 de octubre de 1791, f. 136).

- Ovidio, Metamorphoseis (t. III, n. ${ }^{\circ}$ 83, 20 de octubre de 1791, f. 179).

- Aurelio Víctor, Epitome de Caesaribus (t. III, n. ${ }^{\circ}$ 92, 20 de noviembre de 1791, f. 215).

- Suetonio, Doce césares (t. IV, n. ${ }^{\circ} 111,26$ de enero de 1792, f. 65; t. IX, n. ${ }^{\circ} 312,29$ de diciembre de 1793, f. 282).

La mayoría de estas referencias se introducen en cuadros de costumbres, rasgos biográfico s y breves ensayos literarios, aunque también acompañan tratados científicos. En todos, los clásicos juegan un rol de autoridad para validar la veracidad de las afirmaciones y como garantía del estatus cultural - de paso, social - del autor de la nota.

Muy pocas citas requirieron traducción y ninguno de los autores antiguos o sus obras se acompañaba de una nota explicativa. Se entendía que el público lector, miembro de una misma comunidad con los editores del periódico, también los conocía. Los clásicos se constituyeron así en lazos identitarios de un núcleo social e intelectual hispanoamericano de alta jerarquía, conectado a su vez con un tradición cultural e histórica de la que también se sentía parte.

\subsection{Lecturas indirectas de las obras clásicas}

Los diversos artículos del Mercurio Peruano referidos tanto a temas locales - la historia de una provincia, la caracterización de un río, las costumbres de una población-, como a análisis científicos, se apoyan recurrentemente en exempla de la historia de Grecia y Roma antiguas. En su mayoría, dichas alusiones no indican su fuente, presuponiéndose el reconocimiento de los personajes mencionados por parte del público lector. Terpandro y Orfeo son emblemas de la música (MP, t. II, n. ${ }^{\circ} 42,26$ de mayo de 1791, f. 64; t. III, n. ${ }^{\circ}$ 101, 22 de diciembre de 1791, f. 290); Heliogábalo, paradigma de megalomanía (MP, t. V, n. ${ }^{\circ} 168,12$ de agosto de 1792, f. 239); Licurgo y Solón, así como las póleis de Esparta y Atenas, son legisladores y sistemas modélicos (MP, t. V, n. ${ }^{\circ} 170,19$ de agosto de 1792, f. 257); Cicerón y Demóstenes, paradigmas de la oratoria (MP, t. III, n. ${ }^{\circ} 87,3$ de noviembre de 1792, f. 168; t. IV, n. ${ }^{\circ} 104$, 1 de enero de 1792, f. 6); Octavia y Junia, ejemplos de mujeres virtuosas (MP, t. VI, n. ${ }^{\circ}$ 188, 21 de octubre de 1792, f. 120).

El conocimiento sobre el pasado grecorromano, en especial los anecdotarios y biografías, debió resultar parcialmente de la lectura indirecta de los lectores peruanos, centrada en relatos escritos por historiadores y humanistas desde el siglo XVI en adelante. Así se observa explícitamente en la alusión a las críticas de Sócrates a Alcibíades, rescatada de la Historia de los progresos del entendimiento humano (1775) de Alexandre Savérien (MP, t. V, n. ${ }^{\circ}$ 139, 3 de mayo de 1792, f. 3; también referido en el t. IV, n. ${ }^{\circ} 115,9$ de febrero de 1792, f. 97). La anécdota agregaba una cita de Aelianus III.28, cuya referencia también incluía Savérien, así como otros textos modernos.

Las Memorias de la Academia de Inscripciones y Bellas Letras de Francia también constituyeron fuente para la descripción de las costumbres de los sacerdotes de Grecia antigua (MP, t. XI, n. ${ }^{\circ} 372,27$ de julio de 1794, f. 208), y la Historia universal sagrada y profana de Augustin Calmet ayudó como referencia sobre la historia jurídica romana (MP, t. IV, n. ${ }^{\circ} 115,9$ de febrero de 1792, f. 98).

Para una alusión a la vida de Sócrates se utilizó un Diccionario histórico, cuya edición no se especifica (MP, t. IV, n. ${ }^{\circ}$ 119, 23 de febrero de 1792, f. 127). Como referencia de la biografía de Cicerón se cita la Histoire de M. T. Cicéron de Antoine François Prévost (MP, t. IV, n. ${ }^{\circ}$ 119, 23 de febrero de 1792, f. 131).

A Plinio, los intelectuales peruanos parecen - en ocasiones - haber accedido por vía indirecta. Así se evidencia en una disertación sobre montañas y volcanes, que recurre a la Historia Natural XXXIII 6-7, pero precisando que dicha referencia se había obtenido de Introducción a la historia natural y a la geografía física de España de Guillermo Bowles (1775).

Los filósofos griegos debieron haber sido objeto de lecturas similares. A Aristóteles y a Platón, por ejemplo, se los considera pioneros en el entendimiento de la composición atómica de la materia, pero la disertación que alude a ellos se centra en autores mo- 
dernos, como Newton y Lavoisier, cuyas obras también reconocían la autoridad de los antiguos (MP, t. VI, n. ${ }^{\circ} 184,7$ de octubre de 1792 , f. 85). Una reflexión acerca del lugar de Aristóteles en la historia de la ciencia refrendaba este pensamiento: aun cuando algunos lo menospreciaban a la luz de la ciencia moderna, la universidad lo seguía reconociendo como el fundamento de dicho saber (MP, t. III, n. ${ }^{\circ} 91,17$ de noviembre de 1791, ff. 196-199).

En otros casos, la lectura indirecta se identifica en textos que contienen ecos de la literatura antigua, incluso cuando pueden no constituir una imitación directa. Se trata de casos en los que se vislumbra un vínculo intertextual entre el texto moderno y el antiguo, cuyo ejemplo ha sido objeto de apropiación, manipulación y reinvención por parte del nuevo autor. Ello ocurre con un poema sobre la inundación provocada por el crecimiento del río Rímac. Las lamentaciones del poeta, pródigas en clasicismos, evocan un evidente estilo virgiliano: el pastor Amanto - la voz líricasufre la pérdida de su esposa e hijo, así como la ruina de su antigua Arcadia, tal como Eneas lo hace al perder a Creusa y ver a Troya ardiendo (MP, t. II, n. ${ }^{\circ} 62$, 7 de agosto de 1791, ff. 54-60).

De la misma forma, otro poema lleno de clasicismos evoca el sueño de Escipión y remite al clásico tópico de los sueños al narrar la visión del protagonista sobre diversos personajes y escenas de un cosmos fantástico e idealizado (MP, t. II, n. ${ }^{\circ} 88,6$ de noviembre de 1791, ff. 177-179).

La fuente de inspiración no es clara. Estos poemas, más bien, parecen surgir de estilos y motivos que a los autores resultaban familiares tras haberse educado en la lectura y conocimiento de los modelos literarios de la Antigüedad. Se trata de la apropiación creativa de estilos y enfoques heredados de una suma de lecturas originales o relativas al mundo clásico, que solo podría haber sido posible en quien se hubiera formado en el cultivo de sus principales obras.

\subsection{Lecturas mediadas de las obras clásicas}

Los casos desde los cuales puede percibirse un ejercicio de lectura mediada se dan, mayoritariamente, en los de textos griegos, cuyas citas en el Mercurio Peruano se presentan traducidas al latín. En tal ocurrencia, si bien pudiera ser posible que dichas traducciones las hayan realizado los autores de cada artículo, es factible casi siempre rastrear las citas en textos modernos que, seguramente, constituyeron la fuente directa para el conocimiento indirecto de las obras helénicas por los peruanos.

La Ilíada, en particular, no pudo ser una obra de fácil acceso en su lengua original. Del siglo XVII se registran ediciones en latín, como las de Francisco Javier Alegre (1773 y 1788), de las que pudieron extraerse algunas citas (MP, t. IX, n. ${ }^{\circ} 281,12$ de septiembre de 1793, f. 29). La historia contenida en el poema pudo ser narrada libremente en textos históricos y literarios, y sus versos fueron traducidos al latín de manera fragmentaria en diversas obras. Así se explicaría, por ejemplo, la cita cuius etiam à lingua melle dulcior fluebat oratio [Cuyo discurso fluyó de la lengua, incluso más dulce que la miel] (Il. I.249, en MP, t. III, n. ${ }^{\circ} 42,26$ de mayo de 1791, f. 57), utilizada en compendios de gramática y literatura antiguas, y en los comentarios sobre las cartas de Plinio el Joven, por Joanne Maria Cataneo (1600). En tanto, la cita Calchas Thestorides augurum longe Optimus, qui sciebat, et præsentia, et fucura, et præterita [Calcas Testorida que conocía muy bien los augurios y las cosas presentes, y futuras y pretéritas] (Il. v. 69-70, en MP, t. III, n. ${ }^{\circ} 82,16$ de octubre de 1791, f. 121) estaba contenida, entre otras, en el Veterum Poetarum Graecorum Poemata Aut Poematum de Joannes Schroeder (1733), que incluía una versión grecolatina de los cantos homéricos y de Hesíodo.

La Odisea también es citada en latín (MP, t. IV, n. ${ }^{\circ} 111,26$ de enero de 1792 , f. 64 ; t. VII, n. ${ }^{\circ} 221$, 14 de febrero de 1793, f. 115; t. XI, n. ${ }^{\circ} 372,27$ de julio de 1794, ff. 210-211), quizás de ediciones como Homeri poetarum clarissimi Odyssea de erroribus Ulyxis (1510). En otros casos, sus pasajes se comentan con referencias generales al poema (MP, t. VII, n. ${ }^{\circ} 225,28$ de febrero de 1793, f. 146). El acceso a los poemas de Homero, además, pudo darse a través de traducciones a lenguas romances, tal como la edición que se menciona para rebatir la ceguedad del aedo, apoyándose en un estudio preliminar que precedía a la traducción francesa de Anne Dacier de la Ilíada de 1699 (MP, t. II, n. ${ }^{\circ}$ 57, 21 de julio de 1791, f. 214). 
Algunas obras de Aristóteles, como la Ética a Nicómaco, son mencionadas sin citas o referencias (MP, t. VIII, n. ${ }^{\circ}$ 245, 9 de mayo de 1793, f. 17). Otras debieron haber sido objeto de lecturas mediadas. Meteorologica (MP, t. VIII, n. ${ }^{\circ}$ 272, 11 de agosto de 1793, f. 245) y Praesens per somnum o De la adivinación por el sueño (MP, t. V, n. ${ }^{\circ}$ 148, 3 de junio de 1792, f. 77) se citan con referencia explícita a la fuente antigua, pero la cita de esta última obra es también una que Benito Feijoo había utilizado en su Teatro crítico universal XXI.83. Algo similar ocurre con una cita a la Política VIII.6 (MP, t. II, n. ${ }^{\circ}$ 188, 21 de octubre de 1792, f. 115), que pudo haberse conocido en ediciones latinas de la obra, como la de Leonardo Arentino (1492).

Similar ejercicio puede suponerse de una cita latina a Diógenes Laercio (MP, t. VIII, n. ${ }^{\circ}$ 246, 12 de mayo de 1793, f. 32), que igualmente se utilizó en obras modernas como Historiæ et præcepta selecta. In usum juventutis Christianæ (1748) y Selectæ e profanis scriptoribus historiæ (1771).

Asimismo, Antígona de Sófocles se cita en latín, para complementar su paráfrasis en español (MP, t. III, n. ${ }^{\circ}$ 97, 8 de diciembre de 1791, f. 250). Otros, en cambio, son comentados con referencia a la fuente original, pero sin mayores precisiones. $\mathrm{Al}$ ser escasamente citados, podríamos suponer que algunos autores clásicos se conocían por mediación de otros comentaristas. Así ocurre con Tucídides (MP, t. III, n. ${ }^{\circ}$ 78, 2 de octubre de 1791, f. 79), Heródoto (MP, t. III, n. ${ }^{\circ} 78,2$ de octubre de 1791, f. 77) y Plutarco (MP, t. III, n. ${ }^{\circ} 78,2$ de octubre de 1791, f. 79).

No obstante, llama la atención que, en una nota de colaboración sobre un periódico de Santa Fe, se advierte que una cita asociada a Tucídides no había podido hallarse ni refrendarse por los editores del Mercurio Peruano en la Historia de la Guerra del Peloponeso (MP, t. III, n. ${ }^{\circ} 87,3$ de noviembre de 1791, f. 168). Esto sugiere que el trabajo de citación y paráfrasis, directo o mediado, era prolijo y respetuoso de las fuentes.

Con todo, las lecturas mediadas que pueden identificarse con mayor frecuencia se encuentran en los artículos dedicados a asuntos médicos y se concentran en aforismos de Hipócrates y Galeno. Ambos fueron voces de autoridad en la disciplina para el mundo moderno y parece ser que los intelectuales peruanos accedieron a su obra por la vía de citas, comentarios, traducciones y alusiones realizadas por autores modernos, así como en historias y enciclopedias de anatomía (MP, t. VII, n. ${ }^{\circ} 221,14$ de febrero de 1793, f. 116). En menor medida, a ellos también se sumaba Celso.

Hipócrates es aludido y citado en latín con sus referencias a pie de página, pero las citas suelen coincidir con algunas incluidas en tratados europeos de ciencia y medicina, y especialmente en compendios de aforismos. Así ocurre con la cita Qui utero gerunt, iis os uteri conniver [Quienes llevan útero, incluido los oviductos] (MP, t. II, n. ${ }^{\circ} 45,5$ de junio de 1791, f. 89), contenida en los Aphorismos, De Cognoscendis et Curandis Morbis de Gerardus Van Swieten y Herman Boerhaave (1764).

En otros casos, la cita latina viene acompañada de una nota al pie que indica su fuente moderna, como ocurre con Cirugía Universal de Juan Fragoso (Madrid, 1586), que contenía una versión latina de los aforismos quirúrgicos hipocráticos $\left(\mathrm{MP}, \mathrm{t} . \mathrm{V}, \mathrm{n} .{ }^{\circ}\right.$ 148, 3 de junio de 1792, ff. 74, 76-77; t. VI, n. ${ }^{\circ} 198,25$ de noviembre de 1792, f. 208), y con Praxis Medica ad usum scholae Valentinae de Andrés Piquer (1766) (MP, t. VI, n. ${ }^{\circ}$ 198, 25 de noviembre de 1792, f. 202). En otros pasajes se indica genéricamente que la fuente corresponde a un libro de aforismos (MP, t. III, n. ${ }^{\circ}$ 82, 16 de octubre de 1791, f. 122; t. VI, n. ${ }^{\circ} 197,22$ de noviembre de 1792, f. 196; t. VII, n. ${ }^{\circ} 225,28$ de febrero de 1793, f. 147).

Diferente es el caso de referencias directas a la fuente hipocrática original, que permiten admitir la posibilidad de que algunas obras del médico griego hayan sido leídas directamente por los intelectuales peruanos, aun mediante versiones latinas (MP, t. XI, n. ${ }^{\circ}$ 371, 24 de julio de 1794, ff. 196-197). El Epidemion biblia hepta, traducido como De morbis popularibus, contaba con versiones modernas como la de Herman Croeser (1531), que pudieron ser conocidas en Hispanoamérica. Y así, el libro es aludido en el Mercurio Peruano (t. III, n. ${ }^{\circ}$ 82, 16 de octubre de 1791, f. 121; t. III, n. ${ }^{\circ} 102,25$ de diciembre de 1791, ff. 293 y 296-297; t. V, n. ${ }^{\circ} 167,9$ de agosto de 1792, f. 232. Se cita Epidemias en t. VII, n. ${ }^{\circ} 226,3$ de marzo de 1793, f. 152). En otros casos, pueden haber sido recogidas de compendios, como Hippocratis opera omnia de Jano Cornario (1737). 
Igualmente, el Liber de locis in homine tuvo versiones en latín, como la edición comentada por Francisco Perla (1632). No obstante, la cita a esta obra utilizada en el Mercurio Peruano coincide con una recurrente en tratados médicos modernos. Finalmente, en algunos casos, Hipócrates es mencionado como voz de autoridad, pero a partir de paráfrasis con referencias generales a la fuente original (MP, t. IV, $n .^{\circ}$ 110, 22 de enero de 1792, f. 55).

Por su parte, algunas obras de Galeno, como De tumor praeternat (MP, t. VI, n. ${ }^{\circ} 197,22$ de noviembre de 1792, f. 190) y De curandi ratione (MP, t. III, n. ${ }^{\circ} 102,25$ de diciembre de 1791, f. 296), son citadas como si se recurriera a la fuente directa. Sin embargo, se trata de citas que podían hallarse en tratados como Abscessum Recondita Natura de Marco Aurelio Severino (1724 y 1763). En otros casos, Galeno fue leído a través de obras como In Galeni librum de ossibus doctissima et expectatissima commentaria (1603) de Giovanni Filippo Ingrassia (MP, t. V, n. ${ }^{\circ}$ 149, 7 de junio de 1792, f. 83), De medicorum principum historia (1643) de Abraham Zacuto (MP, t. V, n. ${ }^{\circ}$ 168, 12 de agosto de 1792, f. 239) o en compilaciones de aforismos (MP, t. III, n. ${ }^{\circ} 102,25$ de diciembre de 1791, f. 293; t. IV, n. ${ }^{\circ} 111,26$ de enero de 1792, f. 62). Y en algunas ocasiones, es comentado mediante paráfrasis con referencias genéricas (MP, t. VII, n. ${ }^{\circ} 221,14$ de febrero de 1793, f. 113).

La obra de Celso, finalmente, fue conocida por los autores peruanos por mediación de Andrés Piquer y su Praxis Médica (MP, t. V, n. ${ }^{\circ}$ 148, 3 de junio de 1792, f. 78) y, tal como con los clásicos anteriores, las citas cuya referencia se vincula a la fuente latina en el periódico, también pueden hallarse en obras compilatorias, como Medici Antiqui Omnes (1547) (MP, t. VI, n. ${ }^{\circ} 198,25$ de noviembre de 1792, f. 204), o en tratados como Medicinae Pars Prior de Luca Tozzi (1681) (MP, t. VI, n. ${ }^{\circ}$ 198, 25 de noviembre de 1792, f. 199).

En términos generales, no hubo textos de carácter científico que solo se apoyaran en autores de la Antigüedad. Si bien algunos eran considerados padres de la ciencia, su valoración se realizaba filtrada por el saber moderno e ilustrado. Los clásicos de la ciencia seguían constituyendo referentes ineludibles, pero a diferencia de los clásicos literarios, su valor y saber únicamente se completaban con el progreso alcanza- do en los siglos más recientes, mediador entre el pasado antiguo y el mundo intelectual del Perú colonial.

\section{Clásicos: voces de autoridad y princi- pios de identidad en el Mercurio Peruano}

En junio de 1791, el Mercurio Peruano inició una polémica con un nuevo impreso titulado Semanario Crítico a cargo de fray Juan Antonio Olavarrieta. El conflicto surgió de mutuos cuestionamientos sobre la certeza de los conocimientos expuestos por los autores de los artículos publicados en estos periódicos. Se trataba de una batalla retórica por la autoridad intelectual y cultural de los implicados, lo que traslucía un esfuerzo por legitimarse como voces autorizadas en la comunidad letrada peruana.

Los argumentos podrían parecer anecdóticos, pero entre ellos surgían nuevamente los que referían a materias del mundo antiguo. Desde el Mercurio Peruano, se mofaban de los escasos conocimientos de Olavarrieta en este ámbito, acusándolo de ignorante. Podemos asumir que, siendo los estudios de latinidad la base de la formación académica de la intelectualidad colonial, carecer de conocimientos en el área invalidaba, finalmente, toda la educación del afectado:

Atribuye tratados de Poetica á Dracon, á Terpandro, á Homero, \&c. P. mio, el primero fue un legislador, el segundo un músico, y el tercero el autor de dos Poemas épicos: ninguno de estos, ni los demas que cita no sin error, escribió sobre el Arte Poética [...] De paso sepa el Maestro de nuestros Cómicos, que Livio Andronico fue un Autor solo, y no dos, como cree, y asentó en su lindísima disertación. (MP, t. II, n. ${ }^{\circ}$ 50, 23 de junio de 1791, f. 139)

Los clásicos formaron parte de la identidad de la comunidad intelectual y letrada del virreinato del Perú. Sus miembros, personalizados en las letras del Mercurio Peruano, se representaban a sí mismos como herederos de la tradición clásica y de sus bienes culturales. Un artículo sobre la reunión de la Academia de los Poetas de Lima, presentada en el periódico, da cuenta de ello. Su descripción anula los caracteres locales e inserta a esta comunidad en el universo cultural fundado por la literatura clásica: 
Los Sabios miembros de tan harmoniosa Sociedad ocuparon sus brillantes asientos. Cada una de las nueve fecundas Musas se habia formado firme habitacion en sus amantes Académicos. Favorecidos estos del Sabio Apolo, é mundados por las dulces aguas de Helicona, se preparaban ya á las mas felices producciones. (MP, t. II, n. ${ }^{\circ}$ 52, 3 de julio de 1791, f. 150)

Las alusiones y citas a obras grecorromanas en el Mercurio Peruano evidencian la familiaridad de los autores y lectores del periódico con la cultura clásica. Esta formaba parte de su universo cultural, de su lenguaje y cosmovisión, constituyendo un elemento de identidad como comunidad de élite y de pertenencia a una tradición que trascendía los márgenes locales del mundo colonial.

Los modos de aproximación al mundo antiguo por parte de la sociedad letrada de Perú fueron múltiples, complejos y dinámicos. Los artículos del periódico demuestran que, ya fuese a través de lecturas directas, indirectas o mediadas, el conocimiento de dicha comunidad sobre los clásicos fue amplia y variada, y alcanzó un nivel de inteligibilidad activa que permitió a los intelectuales peruanos apropiarse de las letras antiguas para renovar sus sentidos en función de sus propios intereses e ideas. En ello consiste, justamente, el ejercicio de la recepción: el de una lectura activa y creativa que permite la actualización permanente de los textos clásicos.

\section{Notas}

1 Este artículo forma parte del proyecto FONDECYT 1180056.

2 La Sociedad de Amantes del País fue una asociación surgida por iniciativa de José Baquíjano y Carrillo junto con destacados intelectuales ilustrados que, siguiendo la tradición ibérica, organizaban tertulias y disertaciones. Las Sociedades eran instituciones externas a la administración, sin embargo, fungían como una instancia de apoyo a la misma, desarrollando tres objetivos esenciales: asesoría y apoyo al gobierno, fomento de la educación y la economía regional, y servir de centros difusores de conocimientos (García, 1988; Windler, 1997). La Sociedad de Amantes del País de Lima estuvo compuesta por treinta académicos que solicitaban su incorporación a través de disertaciones, las mismas que constituían la base de las publicaciones del periódico el Mercurio Peruano.

3 Si bien no registra datos de edición, podemos suponer que esta obra contenía una recopilación, traducción y comentarios de los capítulos de Historia natural dedicados a la fauna. Se trata de un modelo que puede observarse en Traducion de los libros de Caio Plinio Segundo, de la historia natural de los animales de Geronymo de Huerta (1599 y 1602), que incluía una introducción del traductor, con una reflexión sobre el mundo como creación de Dios, enmarcando así esta obra en la cosmovisión cristiana. Cada fragmento se seguía de comentarios y notas vinculantes a otras obras antiguas, como las de Aristóteles, permitiendo una aproximación indirecta a otros autores.

4 Si bien no hemos hallado ejemplares con este título, suponemos que su estructura era similar a otras compilaciones parciales de Historia natural a partir de un eje temático, en este caso, la pesca, abordada por Plinio en los libros VII, IX y XXXII.

5 Aunque no se especifican los datos de edición, bibliotecas de España y Perú poseen ejemplares de traducciones de obras de Séneca al romance. Algunas constituyen compilaciones, como Los cinco libros de Séneca en Romance (Navarra, 1530), que contiene en su cuarta parte, sentencias morales o proverbios. Otras ediciones, como una de Sevilla de 1528, ofrecían sentencias morales escogidas entre las diversas obras de Séneca.

6 En adelante, MP.

7 Ejemplos de estas Propositiones se guardan en el Fondo Reservado de la Biblioteca Pedro Zulen, Universidad Nacional Mayor de San Marcos, Lima-Perú. En el Mercurio Peruano (t. III, n. ${ }^{\circ}$ 91, 17 de noviembre de 1791, ff. 198-203), Toribio Rodríguez, 
rector del Real Convictorio de San Carlos de Lima, cuestionaba que las lecturas a defender en los exámenes fuesen Physico audito, De Coelo y De Generatione de Aristóteles, proponiendo, en cambio, la lectura de obras más clásicas: Metafísica, Lógica y Ética.

8 Así lo explica el periódico londinense The Monthly Review que, en 1806, tradujo al inglés este artículo del Mercurio Peruano, en una reseña sobre el libro de R. Phillips, The Present State of Peru, que, a su vez, se habría basado en los artículos del periódico limeño.

9 La cita en el periódico peruano omite el pronombre relativo quae y altera el orden de la oración, antecediendo el verbo est al sustantivo maximum.

10 Ejemplos son Examen chymico-médico de Antonio Ramírez (Pamplona, 1768, p. 72) y Aphorismos de cognoscendis et curandis de Gerardi van Swieten (1753, t. III, p. 386).

11 El artículo indica como fecha de edición del Corpus poetarum el año 723, pero es probable que se trate de 1723, considerando que para el siglo XVIII se registran diversas compilaciones literarias. Uno de ellos, Corpus Omnium Veterum Poetarum Latinorum (Londres, 1721), contenía los versos de Laberio y quizás el Mercurio Peruano hace referencia a esa edición.

12 Ejemplo es Principios geográficos aplicados al uso de los mapas, de Tomás López (1783).

13 Por ejemplo, en la Bibliotheca sacra seu Thesaurus Scripturae canonicae de Petrus Ravanellus (1660); Collegii disputatorii publici exercitatio I, exhibens nonnullas observationes philologicas, de Balthasar Ludwig Eskuche (1738) y en Suidas, cuius integram latinam interpretationem conscripsit, de Aemilius Portus (1619 y 1630).

14 Plinii Caecilii Secvndi Novocomensis, Epistolarvm libri X, Génova, 1600, p. 63.

15 Heródoto es citado en latín en el t. VII, n. ${ }^{\circ} 221,14$ de febrero de 1793, f. 116, aunque dicha cita también se halla en Demostración critico apologetica del theatro Critico Universal de Martín Sarmiento (1757).

16 Se trata de la Mihi quidem videtur principium corporis nullum esse..., que también se registra con su respectiva referencia en obras como, entre otros, el Theatro chyrurgico anatomico del cuerpo del hombre viviente de Francisco Suárez de Ribera (Madrid, 1730) y Uso y abuso del agua dulce potable interna, y externamente practicada en estado sano y enfermo, de José Ortiz Barroso (Sevilla, 1733).

\section{Referencias bibliográficas}

BNP-Biblioteca Nacional del Perú. (1951). Lo que se estudiaba en San Marcos durante el siglo XVIII. Mar del Sur, 18, 143-146.

Barei, S. (2019). ¿Qué leemos cuando no leemos? Telar, 23, 15-23.

Burga, M. (1969). Nueve bibliotecas jesuitas en el momento de la expulsión (1767). (Tesis de Grado), Universidad Nacional Mayor de San Marcos. Lima, Perú.

Cisneros, L. y Guibovich, P. (1982). Una biblioteca cuzqueña del siglo XVII. Histórica, VI (2), 141-171. http://revistas.pucp.edu.pe/index.php/historica/article/ view/8004/8295

Clément, J. (1983). La Révolution française dans le Mercurio Peruano. Caravelle, 54, 137-151. https://doi.org/10.3406/carav.1990.2422

Clément, J. (1990). Bourgeoisie créole et Lumières: le cas du 'Mercurio peruano' (17901795). (Tesis doctoral), Université de la Sorbonne Nouvelle-Paris III. París, Francia.

Fischer, S. (2004). A History of Reading. Londres: Reaktion Books.

García Ruipérez, M. (1988). Nuevas aportaciones al estudio de las sociedades económicas de Amigos del País. Madrid: Consejo Superior de Investigaciones Científicas.

Gazmuri, S. (2017). Los modelos políticos de la antigüedad clásica y su papel en los discursos republicanos en Chile (1810-1833). Estudios Avanzados, 27, 37-53.

González, C. (1996). Los libros de los españoles en el virreinato del Perú. Siglos XVI y XVII. Revista de Indias, LVI (206), 7-47. https://doi.org/10.3989/revindias.1996. i206.816

González, C. (1997). Consideraciones sobre el comercio de libros en Lima a principios del siglo XVII. Anuario de estudios americanos, 54 (2), 665-692 https://doi. org/10.3989/aeamer.1997.v54.i2.391 
Guibovich, P. (2005). Alcances y límites de un proyecto ilustrado: la Sociedad de Amantes del País y el Mercurio Peruano. Histórica, XXIV (2), 45-66. http://revistas. pucp.edu.pe/index.php/historica/article/view/1277

Guibovich, P. (2019). Libros y lectores. Circulación y consumo de la literatura del Renacimiento europeo en el virreinato peruano, siglos XVI y XVII. Telar, 22, 37-47.

Hampe, T. (1987). La difusión de libros e ideas en el Perú colonial. Análisis de bibliotecas particulares (siglo XVI). Bulletin Hispanique, 89, 55-84. https://doi.org/10.3406/ hispa.1987.4613

Hampe, T. (1990). Libros profanos y sagrados en la Biblioteca del Tesorero Antonio Dávalos (Lima, 1583). Fenix, 36-37, 125-145. https://doi.org/10.51433/fenix-bnp.1990-1991.n36-37.p125-145

Hampe, T. (1996). Bibliotecas privadas en el mundo colonial. Madrid: Iberoamericana.

Hardwick, L. (2003). Reception studies. Greece \& Rome, 33. Oxford: Oxford University Press.

Leonard, I. (1942). Best Sellers of the Lima Book Trade, 1583. The Hispanic American Historical Review, 22, 5-33. https://doi.org/10.2307/2507009

Martindale, C. (1993). Redeeming the Text: Latin Poetry and the Hermeneutics of Reception. Cambridge: Cambridge University Press.

Medina, J. (1966). La imprenta en Lima (1584-1824). Santiago: Fondo histórico y bibliográfico José Toribio Medina.

Mercurio Peruano. (1964). Mercurio Peruano. Edición facsimilar. Lima: Biblioteca Nacional del Perú.

Ojeda, R. (2015). El Mercurio Peruano del siglo XVIII: la Sociedad de Amantes del País y la prensa de llustración. Comunifé. Revista de Comunicación Social, XV (15), 5973. https://doi.org/10.33539/comunife.2015.n15.1837

Orellana, E. (1759). Instrucción de la lengua latina o Arte de adquirirla por la traducción de los autores, compuesta para la particular enseñanza de unos niños. Lima: Oficina de los Niños Huérfanos.

Orellana, E. (1760). Lugares selectos de autores latinos de prosa más excelentes para exercicio de la traducción. Lima: Imprenta de los Huerphanos.

Osorio, I. (1980). Floresta de gramática, poética y retórica en Nueva España (15211767). Ciudad de México: Universidad Nacional Autónoma de México.

Poupeney, C. (2009). Hacia una cartografía de la ilustración americana: los pliegues de la escritura en el Mercurio Peruano. Revista de crítica literaria latinoamericana, XXXV (70), 165-182.

Ratio Studiorum. (1635). Ratio atque Institutio Studiorum Societatis Jesu. Auctoritate Septimae Congregationis Generalis aucta. Antverpiae apud Joan Meursium. Salamanca: Universidad de Salamanca, Fondo Antiguo, 10366-46051.

Rivara de Tuesta, M. (1999). La influencia de los clásicos en la filosofía colonial peruana. Fray Jerónimo de Valera (1568-1625). En T. Hampe (Ed.), La tradición clásica en el Perú virreinal (pp. 47-65). Lima: Universidad Nacional Mayor de San Marcos.

Solís, M. (2005). La obra de José Rossi y Rubí en el Mercurio Peruano: búsqueda y creación del lector criollo ilustrado. (Tesis de Magíster). Universidad de Montreal, Montreal, Canadá.

Taboada, H. (2014). Centauros y eruditos: los clásicos en la Independencia. Latinoamérica. Revista de estudios latinoamericanos, 59, 193-221. https://doi.org/10.1016/ S1665-8574(14)71730-2

The Monthly Review. (1806). The Monthly Review, volumen L. Londres: T. Becket.

Vásquez, C. (1999). La Ratio: sus inicios, desarrollo y proyección. Revista Portuguesa de Filosofía, 55 (3), 229-252. https://www.jstor.org/stable/40337390

Villalobos, A. (2012). La enseñanza de la historia universal antigua: participación y tipología de los Manuales de Historia en Chile republicano, 1810-1876. Revista de Historia Americana y Argentina, 52 (2), 11-40.

Willen, G. (1956). Algunas bibliotecas privadas de Lima a través de los inventarios de bienes (1800-1821). Lima: Universidad Nacional Mayor de San Marcos.

Windler, C. (1997). Élites locales, señores, reformistas. Redes clientelares y monarquía hacia finales del Antiguo Régimen. Sevilla: Universidad de Sevilla.

Zeta, R. (2000). El pensamiento ilustrado en el Mercurio Peruano (1791-1794). Piura: Universidad de Piura. 